\title{
"Fitas em chammas": cinema, imprensa e sensacionalismo na Belle Époque carioca
}

"Films on Fire": Cinema, Press and Sensationalism in Rio de Janeiro's Belle Époque

Pedro Vinicius Asterito Lapera*,**

\section{Resumo}

Este artigo analisa a cobertura jornalística sobre incêndios em cinemas na virada para o século XX, quando emergiram alguns traços estruturantes da sociedade carioca no tocante ao consumo cinematográfico e ao papel da imprensa no Rio de Janeiro. A questão principal é: de que modo o sensacionalismo operou como chave de leitura desses incêndios? Partimos da hipótese de que o sensacionalismo pode ser visto como uma prática de comunicação entre diversos grupos sociais, na medida em que suas marcas perpassam diferentes formas de experimentar a modernidade. Buscaremos compreender como o sensacionalismo foi articulado como uma chave de leitura na relação com o consumo cinematográfico, em um momento histórico no qual hierarquias de classe, gênero e raça saíram reforçadas pela lógica da nova ocupação do espaço urbano.

Palavras-chave: cinema; sensacionalismo; Belle Époque; imprensa.

\section{Abstract}

This article analyzes the journalistic coverage on fires that had place in cinemas in the turn of the twentieth century, when some structuring traits of Rio de Janeiro's society emerged in relation to cinematographic consumption and to the role of the press. Our main question is: how was sensationalism used as a key factor in the interpretation of these fires? Our hypothesis is that it can be seen as a practice of communication between different social groups, since its marks permeate different ways of experimenting modernity. We will try to understand how sensationalism was articulated as a key of interpretation in relation to cinematographic consumption, in a historical moment in which hierarchies of class, gender and race were reinforced by the logic of the new occupation of the urban space.

Keywords: cinema; sensationalism; Belle Époque; press.

\footnotetext{
* Universidade Federal Fluminense (UFF), Programa de Pós-Graduação em Cinema e Audiovisual, Niterói, RJ, Brasil.

** Biblioteca Nacional (BN), Centro de Pesquisa e Documentação, Rio de Janeiro, RJ, Brasil. plapera@ gmail.com <https://orcid.org/0000-0002-7547-1566>
} 
Musa Travessa

Na capital, pegou fogo n'um cinema.

Foi-se o cinema; pegou fogo em tudo,

Foi no Rio Branco, e da grande queima Não salvou sómente o chanceller graúdo.

E ainda mais a fita: Paz e amor

Do Nilo? Não se sabe. E o Chantecler

Também salvou-se, não sei se por fervor

Das orações do amestrado Foscleri.

Pirralho $^{1}$

Na primeira década do século XX o Rio de Janeiro passou por uma transformação urbana radical. Sob o comando do prefeito Pereira Passos, ruas estreitas e povoadas por habitações consideradas insalubres e indignas de uma cidade civilizada cederam espaço à larga Avenida Central e a diversos signos da modernidade.

Nesse projeto de modernidade, as diversões ocuparam lugar central. Teatros, espetáculos circenses, cafés-concertos e exposições como a de 1908, dentre outros, canalizavam o tempo livre dos cidadãos cariocas - sobretudo os das classes mais abastadas - e dos turistas que porventura aqui aportassem.

Os cinemas não ficariam de fora da paisagem do Rio de Janeiro. Havendo projeções cinematográficas desde fins de 1896, as salas voltadas prioritariamente para essa atividade começaram a marcar sua presença com a inauguração do Cinema Parisiense, em agosto de 1907 (Araújo, 1985, p. 198-200), dando origem a uma rápida expansão no número de salas nas áreas centrais e mesmo nos subúrbios mais próximos à linha férrea da Central do Brasil nos anos seguintes.

Essa expansão não ocorreu sem tensões nem disputas em torno do ato de ir ao cinema que, relativamente recente, ainda se encontrava em formação em termos de práticas e códigos socialmente aceitos nesses espaços. Situados entre a regulação imposta pelas autoridades, a ânsia de lucro dos proprietários e os humores e vontades dos espectadores, os cinematógrafos ocuparam muitas vezes as páginas dos jornais como foco do debate público.

Tal como exemplificado no poema satírico e epígrafe deste texto, os incêndios que ocorriam nessas casas de diversões ocuparam lugar privilegiado nos jornais e revistas que circulavam nas primeiras décadas do século XX pelo Rio de Janeiro. Mostrando as terríveis consequências e os momentos de horror vivenciados por espectadores, funcionários ou mesmo moradores dos prédios 
onde se situavam os cinemas, a cobertura jornalística ressoava esses acontecimentos trágicos, colocando em pauta alguns elementos na discussão.

Este artigo se debruça sobre os incêndios em cinemas ocorridos nas primeiras décadas do século XX e a respectiva cobertura jornalística, por considerarmos que nesses momentos emergiram alguns traços estruturantes da sociedade carioca no tocante ao consumo cinematográfico, ao papel da imprensa no Rio de Janeiro após a reforma realizada durante a gestão Pereira Passos, uma verdadeira empreitada civilizatória (Benchimol, 1992), e à configuração das redes de sociabilidade.

As questões que norteiam nosso trabalho são: a) de que modo o sensacionalismo operou como uma chave de leitura desses incêndios?; e, secundariamente, b) como o ato de ir ao cinema era conformado pela disseminação de medos associados a ele? Embora o sensacionalismo seja relacionado ao domínio do popular (Martín-Barbero, 2003, p. 160-168), partimos da hipótese de que ele pode ser visto como uma prática de comunicação entre diversos grupos sociais, na medida em que suas marcas perpassam diferentes formas de experimentar a modernidade a serem destacadas na análise das fontes: o horror e o melodrama.

Mais especificamente, buscaremos compreender como o sensacionalismo foi articulado como uma chave de leitura na relação com o consumo cinematográfico, em um momento histórico no qual hierarquias de classe, gênero e raça saíram reforçadas pela lógica da nova ocupação do espaço urbano. Para isso, dialogamos com a análise já desenvolvida por Enne e Borges (2007) e Enne (2007) a respeito do tema.

Antes de passarmos à discussão, eis uma breve apresentação das fontes. Foram recolhidos 96 documentos em 14 jornais e revistas publicados entre 1897 e 1912, dentre artigos, cartas de leitores e fotos, dentre outros. A maioria das publicações era editada no Rio de Janeiro e tinha circulação nacional, tais como os jornais O Paiz, Gazeta de Notícias e Jornal do Brasil. Todos os documentos foram coletados na Biblioteca Nacional, no acervo físico disponível no setor de Publicações Seriadas e na Hemeroteca Digital. Para o tratamento dessas fontes, optamos pela metodologia do paradigma indiciário, tal como apresentada por Ginzburg (2007), tendo em vista a heterogeneidade do material coletado e a nossa preocupação em buscar conhecer alguns aspectos da experiência concreta dos sujeitos do passado.

Reconhecendo que a dimensão de totalidade dessas experiências não deve ser abandonada, Ginzburg infere que "a existência de uma profunda conexão que explica os fenômenos superficiais é reforçada no próprio momento em 
que se afirma que um conhecimento direto de tal conexão não é possível. Se a realidade é opaca, existem zonas privilegiadas - sinais, indícios - que permitem decifrá-la" (Ginzburg, 2007, p. 177). Assim, essas fontes sobre os incêndios relacionados ao consumo cinematográfico, veiculadas entre fins do século XIX e as primeiras décadas do século XX em jornais do Rio de Janeiro, podem ser consideradas como inseridas em práticas sociais, econômicas e discursivas acessíveis por meio dos indícios deixados pelos sujeitos do passado que pretendemos analisar.

MEdos No MUNDO URBANO DA VIRAdA PARA O SÉCUlO XX: AS PRIMEIRAS COBERTURAS JORNALÍSTICAS DE INCÊNDIOS EM PROJEÇÕES DE IMAGENS (1897-1899)

As primeiras notícias que relataram incêndios durante projeções de imagens nos jornais do Rio de Janeiro começaram a circular logo após as primeiras sessões. Quase um ano após a realização da primeira projeção no Salão de Novidades, na rua do Ouvidor, pelo empresário Paschoal Segreto, em 9 de julho de 1896 (Araújo, 1985, p. 73-76), uma notícia sobre o incêndio em um bazar de caridade em Paris assustou a elite carioca que frequentava esses espetáculos.

Tal fato repercutiu na imprensa carioca, sendo noticiado por veículos importantes como o jornal O Paiz, que tinha plataforma mais liberal, em consonância com as ideias da elite republicana sobre política e economia, e era lido em geral pelos setores médios e pela elite carioca. Mesmo que esse incêndio não tenha ocorrido no Rio de Janeiro, a cobertura jornalística mostrou-se relevante para acessar algumas disposições na fruição de imagens pelo público da época e para traçar o perfil de público que era atraído por esses espetáculos.

Na edição de 28 de maio de 1897, o jornal deu ampla cobertura ao fato, divulgando-o na capa. Alguns aspectos sobre a notícia merecem destaque. Em primeiro lugar, a ênfase no número expressivo de mortos (146 no total), no fato de que a maioria das vítimas eram mulheres, e a identificação dessas vítimas a uma elite parisiense. Por meio de sua narrativa, o jornal busca construir um mecanismo de identificação entre as vítimas e seus leitores:

Paris continua ainda sob o pesadelo horrível da medonha catastrophe que enlutou todas as familias, as mais nobres e as mais distinctas de toda a França e mesmo as côrtes principaes da Europa! Foi o mais terrível incendio deste seculo, 
aquelle que mais victimas fez e sobretudo victimas de tanta nobreza - mortos quando estavam reunidos num tão generoso sentimento: o de alliviar a miseria, o de procurar fazer bem á pobreza. (O Paiz, 28 maio 1897, p. 1)

Há também a publicação do nome completo e do endereço das vítimas apontadas até aquele momento, ampliando a identificação pretendida pela notícia e delimitando o recorte de classe não apenas delas, como também do leitor pretendido pelo jornal em seu horizonte de expectativas (Jauss, 2002).

Como elementos estruturantes da narrativa, uma descrição minuciosa do incêndio, destacando a rapidez com que ocorreu - em menos de 15 minutos - e a própria tecnologia da projeção como a responsável pela tragédia. No caso em questão, uma lâmpada do projetor explodiu em contato com éter e fez o fogo se espalhar rapidamente.

O sofrimento e a impossibilidade de fuga das vítimas também tiveram destaque, uma vez que a notícia valeu-se de detalhes como "cadáveres carbonisados", "troncos sem cabeça", "tripas de fora", "miolos espalhados pela rua", apelando a um sensacionalismo marcado pelo excesso na linguagem e pela representação escatológica, que visava transmitir ao leitor o horror do fato. Com isso, iniciava-se a divulgação de certo medo no ato de ir a uma projeção de imagens que, no final do século XIX, acontecia associada a outros espetáculos, como cafés-concertos, teatros de variedades e números de circo.

Ademais, a matéria de $O$ Paiz colocou o debate a respeito do sofrimento das vítimas, amplificando a marca do sensacional: "Soffreram muito os mortos? [...] - As victimas do Bazar da Caridade deviam ter soffrido muito pouco. Antes da terrivel combustão, quase todas deviam ter caído por terra com synchopes [...]. Além disso houve a asphyxia" (O Paiz, 28 maio 1897, p. 2).

Qualificando o medo como emoção, Delumeau (1989, p. 11-37) sublinhou alguns processos relacionados a ele na modernidade. Ligado à construção de hierarquias sociais e à morte, o autor considera o medo inerente à experiência humana, embora os processos conectados a ele precisem ser histórica e socialmente situados. Em nossa análise, consideramos o sensacionalismo como uma das formas historicamente situadas de produção e de disseminação de medos, com os devidos enquadramentos efetuados pelo sistema de produção capitalista.

Sendo uma experiência cara à modernidade e uma das consequências do modelo de urbanização da cidade de Paris na segunda metade do século XIX (Schwartz, 1999), a espetacularização da morte na cena pública é levada ao extremo neste caso: 
A visita que fizemos no dia seguinte ao Palacio da Industria vai ficar-nos gravada eternamente na memoria! O espectaculo de todos esses cadaveres disformes, de todos esses troncos mutilados, de todos esses horríveis pedaços de entes humanos causa-nos um arrepio por todo o corpo. As melhores descripções não podem dar mesmo a mais leve idéa do que era esse estendal de montões negros de carne carbonisada.

Assim como o espetáculo nas visitas aos cemitérios de Paris no final do século XIX analisados por Schwartz (1999, p. 45-88), podemos perceber na descrição do cronista elementos que pontuam o grotesco da catástrofe e, assim, um apelo ao sensacional pelo horror, representado por "cadáveres disformes", "troncos mutilados", cheiro de corpos em decomposição etc.

Em perspectiva muito semelhante, a Revista Moderna também cobriu o incêndio no Bazar de Caridade. Tendo periodicidade mensal, editada em Paris e voltada para o público de elite carioca, excluía de sua linha editorial artigos de cunho político-partidário e contava com muitas ilustrações (desenhos, gravuras e fotos) e textos assinados por escritores renomados à época, o que encarecia o preço unitário da revista e demonstrava a que tipo de público ela pretendia se dirigir.

O pertencimento das vítimas à elite parisiense foi ainda mais acentuado pela revista, com a publicação da foto da Duquesa de Alençon na matéria como exemplo das mulheres mortas no incêndio. Além disso, destacou-se o fato de que a maioria delas se constituía de esposas, filhas ou irmãs de banqueiros, generais e altos funcionários da burocracia francesa, inclusive contrastando isso à morte violenta: "a rapidez quasi explosiva do desastre, a qualidade das victimas, pertencentes quasi todas ás camadas superiores, visiveis e decorativas da sociedade, e o horror particular desse genero de morte, em contraste tão violento com a vida que lhes asseguravam o nascimento illustre, a riqueza e a posição social" (Revista Moderna, 15 maio 1897, p. 8).

Assim, a demarcação do consumo na projeção de imagens assume sua dimensão ritual ao "usa[r] os bens para tornar firme e visível um conjunto particular de julgamentos nos processos fluidos de classificar pessoas e eventos" (Douglas; Isherwood, 2004, p. 115). Com isso, a projeção se alia ao ato de praticar caridade para marcar ainda mais não apenas o recorte de classe e de gênero desse público alvo da tragédia, mas também a identificação do público leitor da Revista Moderna com as vítimas.

O tom sensacionalista também se fez presente no artigo "O Incendio do Bazar da Caridade", veiculado pela revista. Além de descrições minuciosas a 
respeito da agonia das vítimas, o desenho "Um brazeiro humano" (Figura 1) mostra corpos carbonizados e esqueletos suplicando o auxílio dos bombeiros, que aparecem contendo o incêndio, representando ainda cabeças e troncos.

Figura 1 - Revista Moderna, Paris \& Rio de Janeiro, 15 maio 1897, p. 9.

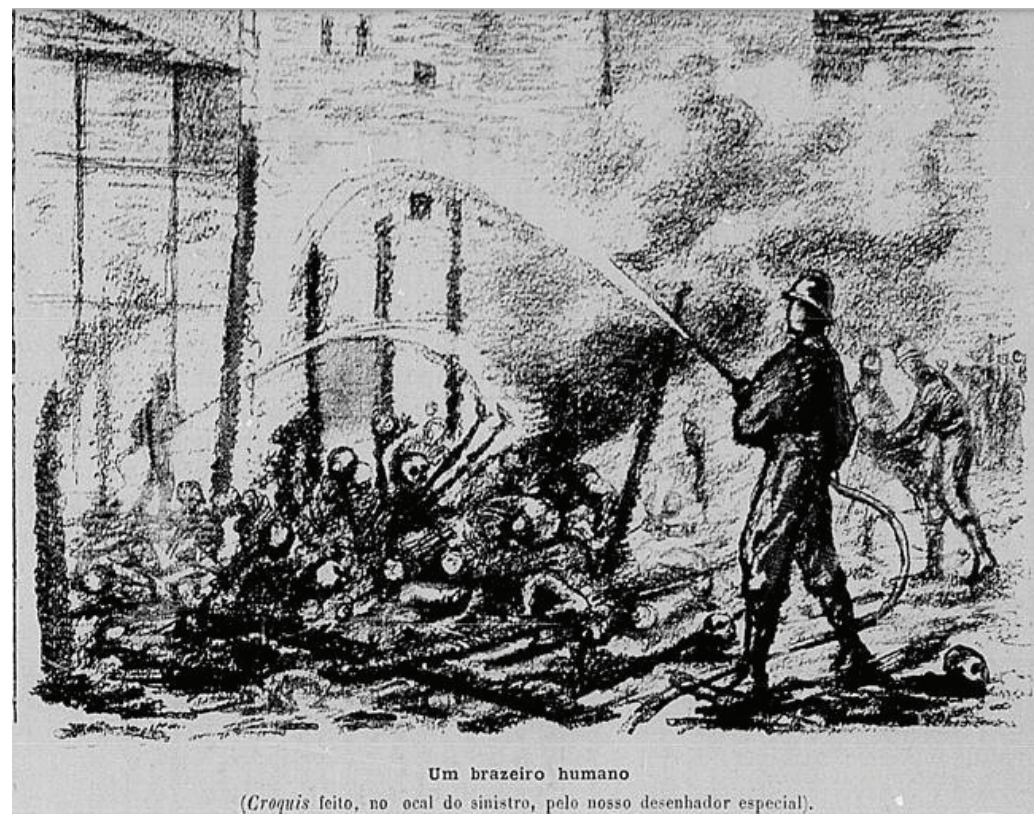

Fonte: Hemeroteca Digital da Biblioteca Nacional.

Podemos extrair alguns pontos da primeira cobertura jornalística sobre incêndios em projeção de imagens na imprensa que circulava pelo Rio de Janeiro. Em primeiro lugar, há o acionamento de um medo do contato com as novas tecnologias (não apenas o projetor cinematográfico, como também bondes, máquinas industriais eram bases para esse medo), pelo horror despertado com as mortes trágicas e publicamente vexatórias. A morte provocada por incêndios era uma das ocasiões em que saía do domínio privado para ocupar a cena pública, tanto na veiculação pela imprensa quanto no impacto nas redes de sociabilidade e nas autoridades (policiais, administrativas e judiciais).

Um dos aspectos centrais na cobertura do incêndio do Bazar da Caridade foi o impacto nas famílias da elite, destacando também o sofrimento dos parentes. Ao analisar a formação da cultura burguesa ao longo do século XIX, Gay ponderou que "o modelo de domesticidade tampouco era recente, tal 
como o da família pouco numerosa, mas sua intensidade era nova e suas possibilidades foram objeto de idealização até então inédita. Segundo a cultura burguesa, a família devia ser considerada o motivo principal da busca de sucesso material" (Gay, 2002, p. 64).

Sendo o medo uma das bases da experiência moderna (Singer, 2001), ele foi veiculado pela imprensa de modo a alertar os leitores sobre os perigos do contato com a projeção cinematográfica, na medida em que os incêndios eram mostrados como uma ameaça à existência de membros da família nuclear, fundamental para a experiência e para a reprodução da burguesia (Gay, 1989; Gay, 2002). Desse modo, o horror acionado pela cobertura jornalística enquadra-se como o excesso a ser comunicado aos leitores, visando à produção de um estado de alerta permanente em relação à tecnologia do cinematógrafo.

A primeira cobertura jornalística de um incêndio ocorrido no Rio de Janeiro por conta de consumo de imagens retomou alguns pontos já considerados. No dia 9 de agosto de 1898, o salão Paris no Rio, onde estava instalado o Animatographo Super Lumière, de propriedade de Paschoal Segreto, o principal empresário do entretenimento carioca na virada para o século XX, foi completamente destruído por um incêndio em razão de falha no projetor.

Apesar de não ter havido vítimas fatais, o jornal Gazeta de Notícias destacou os prejuízos materiais com o incêndio: "No $2^{\circ}$ andar do predio incendiado da rua do Ouvidor n. 141 tinham os Srs. Segreto os ultimos apparelhos vindos da Europa, que custaram cerca de vinte mil francos e outro comprado aos Srs. Arthur Roquet \& C. pela quantia de 2:300\$ [...] e muitos outros objectos" (10 ago. 1898, p. 1), enfatizando a instabilidade das posições sociais no mundo moderno, que poderiam ser alvo de catástrofes e rapidamente invertidas, por conta de prejuízos materiais ou mesmo da ruína financeira, mais um aspecto do horror acionado pelo sensacionalismo, como exploraremos melhor mais adiante.

Por ocasião da reabertura do Animatographo, temos um panorama do público que frequentava a projeção de imagens no Rio de Janeiro no fim do século XIX. O jornal homônimo O Animatographo, ${ }^{2}$ editado e distribuído por Segreto, reproduziu algumas notas veiculadas em jornais no momento de sua reinauguração.

A nota do Jornal do Brasil, replicada pela Gazeta de Notícias - ambas reproduzida em O Animatographo -, sublinhou que "convidou o Sr. Segreto familias distinctas da nossa sociedade e representantes da alta magistratura". O jornal voltado à comunidade italiana no Rio de Janeiro, A Tribuna Italiana, 
destacou o fato de que "assistiam os representantes da imprensa, numerosas senhoras da melhor sociedade, muito público". ${ }^{3}$

Mesmo sendo uma ocasião especial, é possível inferir a que tipo de público as projeções de imagens mantidas por Segreto se destinavam e, por conseguinte, a que classes sociais de leitores se dirigiam as marcas do sensacionalismo em torno da cobertura a incêndios em projeções cinematográficas. Desse modo, começamos a compreender o sensacionalismo fora do domínio estritamente do popular e o inserimos como forma de comunicação na cena pública entre diferentes grupos sociais, em esforço análogo ao de Enne em apresentá-lo “como um processo histórico, formado a partir de fluxos do imaginário, envolvendo um intrínseco jogo entre representações e mediações, e não como um fenômeno isolado, reminiscência ilustrativa de um 'mau gosto de classe' ou pura estratégia de dominação mercadológica” (Enne, 2007, p. 70).

\section{Cinemas após a reforma urbana de Pereira Passos: INCÊNDIOS, PÂNICOS E RUÍNAS NA BELLE ÉPOQUE CARIOCA ${ }^{4}$}

A reforma urbana do Rio de Janeiro empreendida ao longo da gestão Pereira Passos implicou importantes transformações para a cidade. Sevcenko enumerou quatro características que a pautaram: condenação de hábitos ligados à tradição; negação da cultura popular; expulsão das classes populares das áreas centrais; e, por fim, um cosmopolitismo agressivo (Sevcenko, 1983, p. 30).

Um dos objetivos de Passos com a reforma era a afirmação do domínio da então Capital Federal no campo da cultura, compreendida aqui como 'civilização’. Nessa pretensão, os cinemas ocuparam lugar central como a propagação do ideal moderno e do impacto das novas tecnologias na vida urbana. Associadas à transformação da cidade, as salas de cinema eram percebidas em sua relação com a vida civilizada nos moldes europeus, na qual as elites e os setores médios se apropriavam de vários hábitos de consumo (vestimenta, entretenimento etc.) desse modelo na sua forma de experimentar o mundo como classes sociais (Thompson, 2004).

Sobre essa experiência das classes sociais na modernidade, ao se debruçar sobre o operariado na Inglaterra dos séculos XVIII e XIX, Thompson destacou que "a classe acontece quando alguns homens, como resultados de experiências comuns (herdadas ou partilhadas), sentem e articulam a identidade de seus 
interesses entre si e contra outros homens cujos interesses diferem (e geralmente se opõem) dos seus" (Thompson, 2004, p. 10).

Guardadas as devidas proporções em relação ao fenômeno abordado por Thompson, podemos inferir que, por ocasião das primeiras projeções de imagens, houve a presença de um desejo por distinção (Bourdieu, 2011) tanto pelos empresários que exploravam as tecnologias caras à exibição de imagens quanto pelo público de elite que marcava suas diferenças em relação a outras classes sociais - sobretudo as camadas populares, mas também, nesse primeiro momento, em relação aos setores médios. Assim, o primeiro contato com as novas tecnologias de exibição inseriu-se no ethos da elite carioca, configurando um elemento importante para a autoimagem dessa classe, que se percebia como moderna, precursora do progresso e capaz de assumir os rumos de uma nação.

Com a consolidação da presença dos cinemas na paisagem urbana, houve expansão no público que frequentava essa diversão, em comparação com o público mais elitizado das primeiras projeções cinematográficas, como já apontamos na parte anterior. Todavia, esse aumento ocorreu dentro de certos limites impostos justamente pelas características da reforma urbana pela qual a capital havia passado.

Em outro artigo, argumentamos que, em razão de ser a sede de diversos órgãos públicos e também de ser uma cidade com um comércio ativamente em expansão desde o século anterior, o Rio de Janeiro testemunhou a formação de uma classe média que viu no consumo cinematográfico uma oportunidade de afirmar seus valores e suas formas de ver o mundo, sobretudo em relação às classes mais baixas, cuja frequência ao cinema era irregular, em razão de fatores como preço do ingresso, vestimentas usadas no ato de ir ao cinema e localização da maioria dos cinemas nas áreas mais valorizadas (Lapera, 2018).

A imprensa também se inseriu na cena urbana pós-reforma como mediadora na construção da cidade a ser vista pelos seus habitantes. Park (1967) abordou seu papel na conformação de um imaginário urbano e de repertórios em torno da vida nas cidades em expansão nos séculos XIX e XX. Em paralelo ao cinema, foi um meio de comunicação estruturante do ethos urbano e, desse modo, torna-se fonte fundamental para averiguar padrões de consumo e veiculação de ideias e de comportamentos dos sujeitos do passado.

Os incêndios em cinematógrafos poderiam passar semanas ou mesmo meses sendo noticiados, dependendo dos desdobramentos das investigações policiais, e possuíam alguns elementos estruturais: descrição das causas do incêndio, do momento em que ele ocorreu, das mortes em razão dele, dos 
prejuízos causados, do impacto nas redes de sociabilidade e da ação das autoridades municipais, policiais e bombeiros. Para este último aspecto, reservaremos a terceira parte de nossa exposição.

$\mathrm{Na}$ descrição dos incêndios, o apelo sensacional ao poder do fogo era o elemento narrativo de maior destaque: "era um espectaculo digno de ser visto. As labaredas, como si fossem impelidas por uma força invisivel, iam, pouco a pouco, avançando, ameaçando destruir todo um mundo de casas que se erguia á sua frente" (A Época, 21 ago. 1913, p. 2, grifo nosso). A palavra 'espetáculo' era usada comumente para se referir a esses fatos e pode ser percebida como um vestígio de sua importância na quebra da rotina da vida urbana.

As fotos que circulavam pelos jornais mostrando o resultado dos incêndios visavam impressionar os leitores, produzindo medo em relação à tecnologia e ao espaço do cinema.

Figura 2 - Incêndio no Cinema Rio Branco. Gazeta de Noticias, 8 jul. 1910, p. 1.

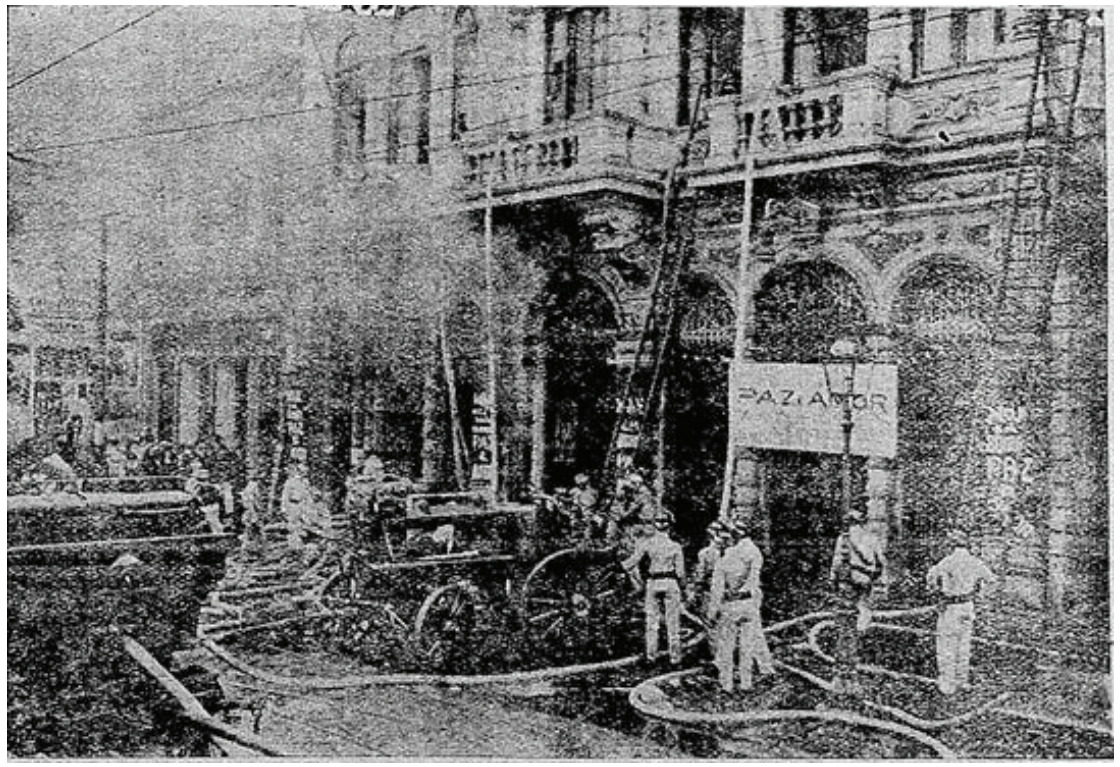

Fonte: Hemeroteca Digital da Biblioteca Nacional. 
Figura 3 - Incêndio no Cinema Brasileiro. A Noite, 9 dez. 1912, p. 2.

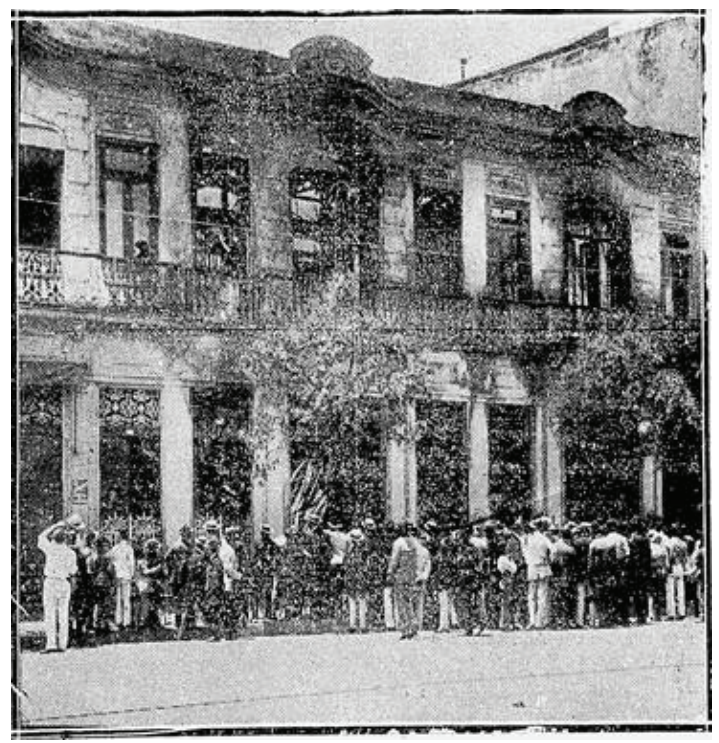

Fonte: Hemeroteca Digital da Biblioteca Nacional.

Na segunda foto, a dimensão de espetáculo dos incêndios saiu reforçada, tendo em vista a multidão aglomerada assistindo ao trabalho dos bombeiros na sua contenção. Além disso, a cobertura jornalística tendia a colocar as fotos na capa ou nas primeiras páginas, em continuidade ao conteúdo da capa, o que ajudava a reforçar a lógica de espetáculo desses eventos.

Em paralelo aos incêndios, outro elemento ganhava destaque: a narração de mortes e os relatos de feridos. A produção de uma identificação com as vítimas nas narrativas jornalísticas passava pela presença de características relacionadas ao sensacionalismo que, nos casos em questão, poderiam resvalar para o horror e/ou para o melodrama.

O jornal A Imprensa narrou a tentativa de fuga dos membros de uma família que morava no sobrado onde estava localizado o Cinema Brasileiro, alvo de um incêndio em 8 de dezembro de 1912:

\section{A morte do dentista}

Depois de passar toda a familia para a casa contigua, o cirurgião dentista dr. Sá Rego, homem de idade avançada e bastante gordo, não poude mais supportar a intensa fumaça que o asphyxiava. 
Ao segurar-se á sacada, querendo pular, caiu para dentro do predio em chammas, onde ficou para não mais se erguer.

Foi uma scena horrivel a que assistimos commovidos, os innumeros espectadores, que se aglomeravam em frente ao predio do ex-Cinema Elite. (9 dez. 1912, p. 1)

Em consonância com esta cobertura, $A$ Noite ( 9 dez. 1912, p. 1) entrevistou a esposa do dentista, com o subtítulo "Os últimos momentos do dr. Sá Rego - morrer para salvar a familia!”, e o jornal A Época também relatou a fuga da família Sá Rego em tom bem parecido (9 dez. 1912, p. 2). Uma imaginação melodramática (Brooks, 1995) foi acionada a partir da representação do sacrifício da figura paterna pela família, ao mesmo tempo que sua morte era narrada com elementos de horror.

$\mathrm{Na}$ ordem burguesa projetada pela Primeira República, a figura paterna era fundamental para a manutenção da família, entidade a ser preservada de convulsões sociais presentes na vida pública. ${ }^{5}$ Sobre a relação entre família e ordem no período, Caulfield argumentou que havia duas concepções de honra sexual que orientavam as práticas jurídicas, médicas, administrativas etc.: "a honra como precedente era a prerrogativa dos homens, a honra como atributo moral (pureza sexual) era restrita às mulheres, e a defesa da honra feminina, uma responsabilidade masculina" (Caulfield, 2000, p. 86). É importante salientar que, em ambas as definições, o homem/pai era a figura central em torno da qual girava a honra familiar.

Assim, a veiculação da morte de um pai de família de classe média ampliava um sentimento de medo em relação ao contato com as novas tecnologias, que afloravam ainda mais um sentimento de instabilidade na vida moderna, além da possibilidade de essa morte violenta vir a ser tornada pública e, com ela, advir uma publicidade vexatória post-mortem. A posição social da vítima ajudava a produzir um sentimento de identificação com ela, por parte dos leitores de jornais, bem como uma projeção de si no momento trágico do incêndio, uma vez que o público leitor de jornais do período era composto em boa parte por segmentos dos estratos médios da população (burocratas, comerciantes, intelectuais/acadêmicos, estudantes etc.).

O jornal O Século publicou uma descrição do corpo do dentista: “O cadaver do dentista Sá Rego foi encontrado completamente carbonisado e removido para o Necroterio. Vimol-o ali. Era uma massa informe, negra, não se podendo distinguir um traço physionomico sequer. Tinha os braços e as pernas curvados" (O Século, 9 dez. 1912, p. 1). Por sua vez, o jornal A Noite 
publicou na capa da edição de 9 de dezembro a foto do corpo carbonizado do dentista, que reproduzimos na Figura 4.

Figura 4 - A Noite, 9 dez. 1912, p. 1.

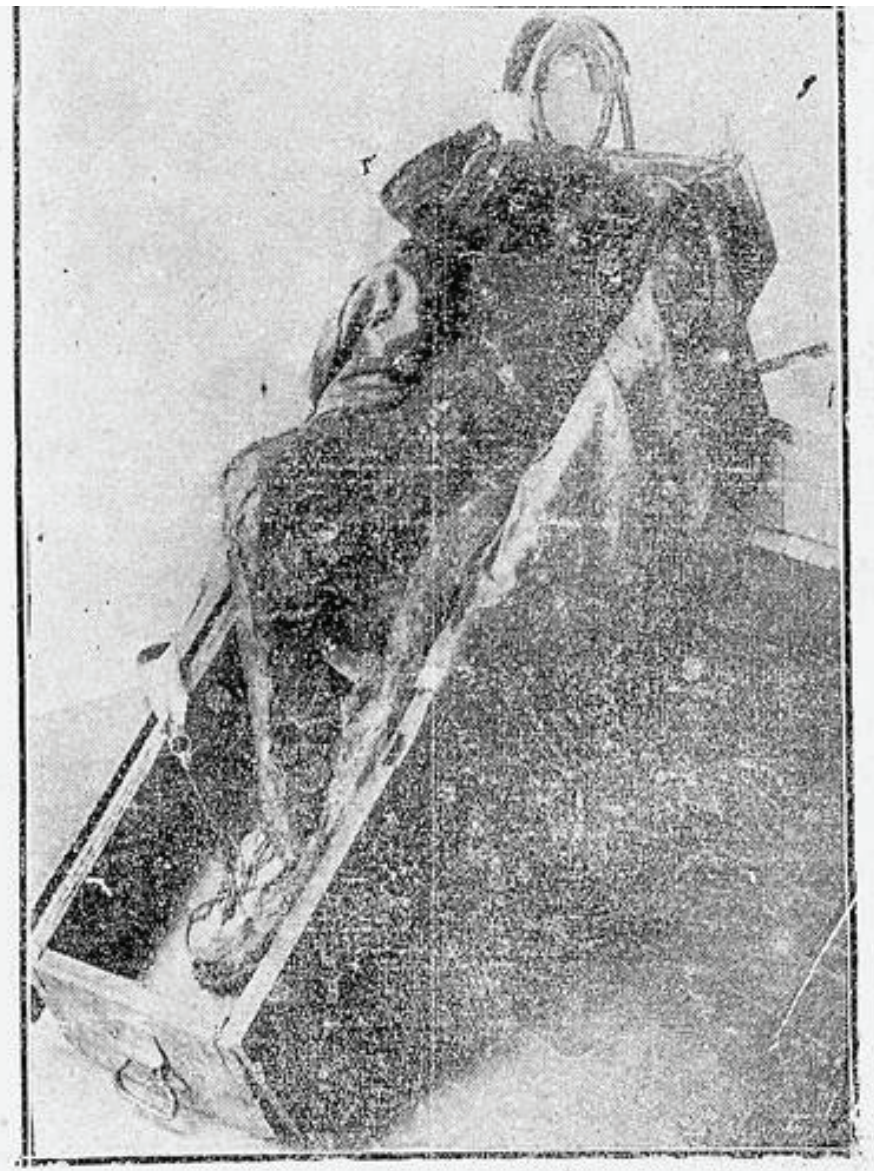

Nóo nas dispensamos de publicar esla gravura para que se ceja o trislissimo resullado da incuria policial. E' o ca laver carbonisado do infeliz cirurgião-dentista Dr. Sá Rcgo, que se sacrificout para scloar a vide dos sets.

Fonte: Hemeroteca Digital da Biblioteca Nacional.

Em resumo: vários jornais dirigidos aos estratos médios e à elite carioca valeram-se de marcas caras ao sensacionalismo em suas narrativas do incêndio no Cinema Brasileiro. Embora o sensacionalismo tenha passado, ao longo do 
século XX, "a ser designado como um gênero isolado, sem conexões históricas, e relacionado depreciativamente a um segmento social" (Enne, 2007, p. 70), podemos verificar que, nas fontes citadas, o sensacionalismo foi uma prática de comunicação que ultrapassou o domínio do popular. A disseminação de um sentimento de medo em relação ao cinematógrafo precisou recorrer a diversos elementos apontados como sensacionalistas, que também foram analisados por Enne (2007, p. 71).

A veiculação de imagens impactantes (corpos queimados e carbonizados, cinemas destruídos) na capa dos jornais é o primeiro aspecto a ser destacado. Por ser um espaço fundamental para a economia visual do meio impresso, a presença dessas imagens na capa revela uma estratégia comercial no sentido de captar a atenção dos leitores para um fato que fugia da lógica cotidiana.

Precisamos sublinhar que foram encontradas ao longo do levantamento para a pesquisa várias notícias de jornais ilustradas por fotos semelhantes em termos de conteúdo, o que demonstra ser uma forma de veiculação bastante conhecida tanto pelos editores de jornais quanto pelo público leitor. ${ }^{6}$ Acompanhada de textos que situavam os fatos usando o excesso como tropos narrativo, as imagens operavam como reiterações dos primeiros, sendo importante sublinhar que a estrutura de repetição presente nas narrativas é fundamental para o sensacionalismo, uma vez que este precisa se valer dela para ser difundido a um número expressivo de leitores.

O uso de manchetes que ressaltavam a destruição e as mortes provocadas pelos incêndios é outra marca do sensacionalismo, sendo este ainda ressaltado por elementos escatológicos na descrição do estado das vítimas - haja vista o uso de palavras e expressões como "massa informe", "tudo torrado", "tripas saltaram pra fora" - e por marcas sensoriais ao longo do texto: "gritos lancinantes", "debatendo-se furiosamente", "não poude mais supportar a intensa fumaça que o asphyxiava".

A dimensão de espetáculo que as marcas de sensacionalismo conferiam aos incêndios em cinemas era ressoada pelo engajamento do público (leitores dos jornais, espectadores de cinemas, transeuntes etc.). A Gazeta de Notícias observou que, após um incêndio, este virou "o assumpto de todas as palestras e muita gente houve que, receiosa, se absteve de ir aos outros cinemas assistir ás sessões. Os curiosos apinhavam-se á frente do predio incendiado, a ver os escombros, fazendo commentarios mais ou menos absurdos a respeito do fogo e das suas consequencias" (9 jul. 1910, p. 2).

A notícia enfatiza o impacto dos incêndios nas disposições de consumo dos espectadores de cinema e também a maneira como aqueles se inseriam na 
espetacularização da cidade, ou seja, eram eventos para serem vistos e propagados pelas redes de sociabilidade de diferentes grupos sociais. Ao contrário das barreiras econômicas representadas pelo preço dos ingressos, pela localização dos cinematógrafos e pela necessidade do uso de vestimentas caras para os padrões de consumo das classes mais baixas, as narrativas sobre incêndios em cinemas poderiam ser rapidamente difundidas em um público bem mais amplo que o dos cinemas.

Fechando o ciclo, nem mesmo o analfabetismo de boa parte da população - um impeditivo à leitura dos jornais - restringia a disseminação desses fatos, na medida em que os rumores se espalhavam pela cidade sem estarem totalmente vinculados aos meios impressos. Assim, o sensacionalismo afirma-se como uma prática de comunicação transversal a diversos grupos. Valendo-se da oralidade como forma de repetição de sua estrutura narrativa e de suas marcas, o sensacionalismo consegue entrar na experiência dos que não estavam presentes nos cinemas alvos das tragédias, nem sequer os testemunharam diretamente. Em suma: ultrapassava o universo dos consumidores dos meios cinema e impresso e ganhava a cena pública de modo muito mais amplo.

Tal fato demonstra que o consumo não pode ser tomado como coerente a priori e corrobora a hipótese desenvolvida por Enne e Borges (2007) de que o sensacionalismo é um fenômeno com diferentes matrizes, que iria confluir para a cultura massiva no século XIX e se destacaria ainda mais no século XX. Acrescentamos que a retórica pejorativa de distinção em relação ao sensacionalismo na análise de produtos e processos culturais - detectada de modo bem preciso e correto pelos autores - tem de ser contraposta ao fluxo de processos de categorização e de sedimentação das hierarquias sociais, o que estamos fazendo ao longo da exposição de nosso argumento.

Colocando de lado a carga pejorativa do termo e verificando as assimetrias e as diferenças no acesso aos produtos e bens (Douglas; Isherwood, 2004), o sensacionalismo pode ser apresentado como uma prática de comunicação reveladora do lugar do lazer em uma sociedade capitalista (Miller, 1987, p. 191), sobretudo se considerarmos o fato de que essa sociedade havia abolido recentemente a escravidão e se projetava em um cenário urbano recém-reformado para acentuar hierarquias de classe e de raça no cotidiano dos cariocas nas primeiras décadas do século XX.

A disposição de tempo livre para a leitura de jornais e a ida ao cinema coadunavam-se com a renda despendida nessas atividades pelos setores médios e pela elite carioca e, em menor escala e sem se consolidar como hábitos de consumo, pelas classes mais baixas. Desse modo, as narrativas de crimes e fatos 
extraordinários que tomavam de assalto a vida urbana e permeavam os filmes (Musser, 1994; Araújo, 1985; Bernardet, 2004) encontravam ressonância e retroalimentação nas práticas do jornalismo das primeiras décadas do século XX, que ampliavam as marcas do sensacionalismo em suas narrativas e, assim, faziam a experiência das classes que acessavam tais meios também ser perpassada por ele.

Outra marca do sensacionalismo presente nessas narrativas era a possibilidade de uma morte social, representada pela ruína e pelos prejuízos nos incêndios. A Imprensa publicou uma notícia em que destacou o infortúnio de um proprietário de cinema: "Na rua, o dono do cinema, sr. José Manoel Gonçalves, que é também sachristão da matriz de Santa Rita, assistia, rodeado de sua familia, à completa ruina, pois tendo montado o cinema havia dias, ainda não tinha colocado no seguro" (10 jul. 1910, p. 4).

Por ocasião do incêndio do Cinema Piedade, localizado no bairro homônimo, ${ }^{7}$ a Gazeta de Notícias também sublinhou a falência de seu dono em razão de um incêndio:

O Cinema Piedade estava seguro até domingo ultimo e o seu proprietario tencionava reformar a apolice respectiva, o que não chegou a fazer. A companhia de seguros certamente não indennisará o prejuizo, o que importa dizer-se que o Sr. Januário Cordeiro de Oliveira, proprietario do cinema incendiado, por questão de alguns dias perdeu na totalidade a sua propriedade. (17 ago. 1911, p. 3)

Em ambas as notas, o tempo é representado como elemento fortuito contra a sorte dos proprietários dos cinemas, a instabilidade das posições sociais na modernidade é ainda mais ressaltada, e uma leitura melodramática (Brooks, 1995) desses eventos é acionada como resposta a ela, no sentido de oferecer explicação a esse azar experimentado pelos sujeitos arruinados.

\section{“Mocinhos" E "Vilões" NO COMBATE A INCÊNDIOS EM CINEMA: O PAPEL DAS AUTORIDAdES NA PRIMEIRA RepÚblica}

Uma imaginação melodramática (Brooks, 1995) também se faria presente na relação entre jornais, leitores, espectadores e as autoridades responsáveis por fiscalizar os cinemas. Em vários editoriais e notícias sobre incêndios veiculados pelos jornais, a polícia foi retratada no polo do 'vilão'. Era apresentada como um órgão no qual imperava o apadrinhamento, os favorecimentos e a corrupção generalizada, a face estatal do arrivismo e do cosmopolitismo 
agressivos apontados por Sevcenko (1983, p. 28-34) como estruturantes da cena pública no Rio de Janeiro da Belle Époque.

Na caracterização da conduta da polícia em sua vilania, um valor é central: a indiferença. Definindo-a como a "rejeição de uma humanidade em comum", Herzfeld (1992, p. 1) investigou como a indiferença perpassou a conduta de agentes estatais historicamente em diferentes Estados europeus, sublinhando uma tensão entre a universalidade dos direitos reconhecida pela ordem jurídica da maioria desses países e a aplicação seletiva e orientada por laços de amizade e parentesco em várias situações de contato entre os cidadãos e a burocracia.

A indiferença da polícia foi o mote da notícia veiculada pelo jornal A Noite a respeito do incêndio no Cinema Elite (que tinha mudado de nome para $\mathrm{Ci}$ nema Brasileiro):

O Rio dá hoje a impressão de uma cidade desgovernada, onde cada um faz o que quer e onde cada um tem de defender-se por suas proprias mãos. [...]

Mais cedo do que suppunhamos, tiveram triste confirmação as nossas palavras. No incendio de hontem, no Cinema Elite, tres vidas foram sacrificadas e só a circumstancia de ser muito diminuta a concorrencia se deve não ser maior o numero de vidas. A policia decidir-se-á agora a providenciar seriamente? Duvidamos. [...] Tendo sabido do sinistro de hontem, S. Ex. provavelmente foi tratar immediatamente... da política do Acre. (A Noite, 9 dez. 1912, p. 1)

O sacrifício caro ao melodrama aparece nas três mortes relatadas, e a indiferença dos agentes estatais a causa direta delas. As marcas do sensacionalismo na descrição hiperbólica (cidade desgovernada) e na ironia que conclui o texto (a política do Acre como objeto irrelevante diante dos incêndios em cinemas, na visão do cronista) amparam a posição moral dos jornalistas, que se colocam acima da corrupção e de favores e como empreendedores morais (Becker, 2008) perante as autoridades públicas na criação e imposição de regras sobre o consumo cinematográfico, na tentativa de evitar o caos e, diante dele, que "cada um [tenha] de defender-se por suas proprias mãos".

Sobre o papel da imprensa no Rio de Janeiro da virada para o século XX, podemos resgatar a análise de Süssekind (2006, p. 24) de que a expansão das técnicas de impressão no final do século XIX foi fundamental na conformação da atividade do jornalismo no período. Por sua vez, Sevcenko (1983, p. 78-118) considerou que o jornalismo era um campo privilegiado para a atuação dos intelectuais, no qual os jornais e revistas operavam como tribunas de ressonância de suas opiniões a respeito de questões sociais, econômicas, políticas e 
de costumes relevantes para a cena pública da então Capital Federal. O autor salienta que o jornalismo era "a nova grande força que absorveu quase toda a atividade intelectual nesse período” (Sevcenko, 1983, p. 99).

Nesse cenário, a imprensa tornava-se uma das principais mediadoras dos interesses da população em relação às autoridades, embora essas demandas tenham caráter classista muito forte em várias ocasiões, como o foi no caso dos incêndios em cinemas, uma vez que a parte mais expressiva do público pagante era composta por sujeitos dos estratos médios. Esses eram, aliás, os grupos a que os jornais de maior prestígio da época se dirigiam preferencialmente.

Como consequência do exposto, os jornais também eram primordiais para a imagem pública das autoridades perante esses grupos e, metonimicamente, para a afirmação dos ideais de civilização e de progresso encampados pela Primeira República que, por ocasião dos incêndios, entravam em choque com a indiferença presente nas relações concretas entre agentes da burocracia e governados. Em suma, a universalidade dos ideais republicanos e o patrimonialismo (Holanda, 2004) das relações concretas na burocracia e no trato de seus agentes quanto à população apareciam interligados, embora em permanente tensão.

Apropriando-se do referencial de Weber, Sérgio Buarque de Holanda ressaltou que "para o funcionário 'patrimonial', a própria gestão política apresenta-se como assunto de seu interesse particular; as funções, os empregos e os benefícios que deles aufere relacionam-se a direitos pessoais do funcionário e não a interesses objetivos" (Holanda, 2004, p. 146), ao passo que um Estado burocrático era pautado - no modelo weberiano - a ações racionais visando a finalidades e a direitos individuais e coletivos, aos quais a conduta dos agentes públicos como indivíduos deveria servir. Em sua análise sobre o Estado brasileiro, Holanda sublinhou a preponderância do primeiro tipo em relação ao segundo. Não discordamos de seu diagnóstico, apenas recordamos que os sujeitos se valiam de práticas referentes aos dois modelos, e disso derivam os choques entre eles, o que é relevante para se pensar as mudanças sociais do período.

Além da indiferença que reside na atuação da polícia, outras características também são ressaltadas pelos jornais. Após o incêndio no Cinema Rio Branco, o jornal Correio da Manhã assim descreveu sua conduta:

Não parece acertado que a policia, tendo para os theatros um regulamento severo, deixe de o pôr em execução também nos cinematographos. Até agora não nos consta que essas casas de diversões, onde a frequencia é muito maior, por ser 
continuada, e muito menores as probabilidades de fuga em caso de um incendio, soffram siquer uma superficial fiscalização das autoridades. $\mathrm{O}$ sinistro do Rio Branco, sejam quaes forem as causas que o motivaram, veiu mostrar que não existe absolutamente um apparelho immunizador que ponha a plateia a salvo dos accidentes facilmente verificaveis nas diversas dependencias de operação. (Correio da Manhã, 11 jul. 1910, p. 1)

A notícia ainda destaca a seletividade da ação da polícia (e da fiscalização da Prefeitura) e faz acusações veladas de corrupção por parte dos órgãos. Por serem uma diversão com status cultural mais elevado que o cinematógrafo - e, acrescentamos, mais cara e com um público mais restrito que o dos cinemas -, os teatros eram alvo de uma fiscalização mais severa. Com isso, se faz uma leitura melodramática da situação, na qual o polo da vilania é ocupado pela polícia e pelos agentes municipais, enquanto os cidadãos são colocados no lugar moral das potenciais ou reais vítimas. Desse modo, o medo do tratamento indiferente por parte da burocracia contra eles surge como mais um a ser disseminado pelo sensacionalismo nos jornais do período analisado.

Ocupando o polo oposto ao da polícia, os bombeiros aparecem nas notícias como um órgão disposto a salvar as vidas dos cidadãos em casos de perigo, sendo os heróis perante a população. Os elogios à ação dos bombeiros eram bastante comuns na imprensa das primeiras décadas do século XX. A título de exemplo, eis o artigo veiculado por A Época, que sublinhou a rapidez com que chegaram ao local do incêndio: "Minutos depois compareciam os pressurosos bombeiros, commandados por um official superior” (21 ago. 1913, p. 2).

Em outra oportunidade, A Imprensa também adotou um tom bastante positivo para tratar da corporação: "Há muito tempo que o Corpo de Bombeiros não faz um serviço tão completo como no incendio de hontem, do qual já o publico tomou conhecimento, em virtude dos boletins dos jornaes" (8 jul. 1910, p. 1). A notícia ainda destacou a importância e a qualidade do trabalho para uma investigação criminal em andamento, um índice de seu prestígio entre os cidadãos do Rio de Janeiro.

O mesmo jornal veiculou fotos dos bombeiros na ação de combater um incêndio em um cinema, sendo eles mostrados de forma altiva, e seu trabalho dotado de um sacrifício comparável ao de um herói, tal como podemos verificar na Figura 5. 
Figura 5 - Fogo em um cinema. A Imprensa, 10 dez. 1910, p. 2.

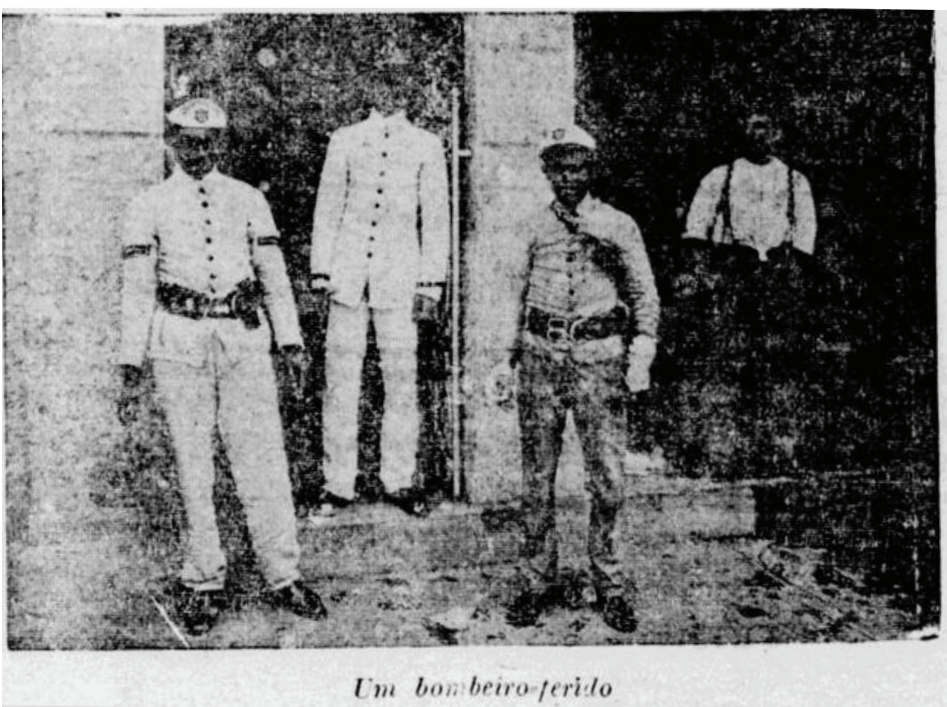

Fonte: Hemeroteca Digital da Biblioteca Nacional.

Além do trabalho em si, os jornais cariocas apontavam os bombeiros como injustiçados dentro da estrutura do Estado brasileiro na Primeira República, com salários baixos e condições precárias de trabalho, o que configura mais um traço melodramático na sua representação como heróis. A Gazeta de Notícias veiculou matéria intitulada "O estado do Corpo de Bombeiros" (22 jul. 1912), apontando diversos problemas enfrentados pela instituição, dentre eles: falta de recursos; não acompanhou o ritmo de expansão e a reforma do Rio de Janeiro; não estava preparado para atender ocorrências fora das áreas centrais, apontando necessidade de criação de subestações. Por fim, o jornal atribui a responsabilidade à inépcia dos deputados, que não aprovavam orçamento para a corporação, e aos administradores que não repassavam verba para ela.

$\mathrm{Na}$ edição do dia seguinte, houve uma entrevista com o comandante interino do Corpo de Bombeiros rebatendo esses pontos, porém acrescentando um dado relevante sobre a ida aos cinemas:

perguntado se não era conveniente a permanencia de uma turma de praças do Corpo de Bombeiros nos cinemas, respondeu o commandante interino que isso seria medida excellente, mas presentemente impraticavel, porque, sendo muitos os cinemas e funccionando de dia e de noite, seriam necessarias muitas praças. $\mathrm{O}$ 
melhor seria que cada cinema tivesse um homem de promptidão para correr ao telephone ao primeiro alarma, ou que cada cinema tivesse uma chave de caixas de aviso. (Gazeta de Notícias, 23 jul. 1912, p. 4)

Essa discussão também é um vestígio de como a segurança pública era vista como primordial sobretudo nas regiões centrais recém-reformadas do Rio de Janeiro. Os jornais atuavam na mediação entre leitores e autoridades, no sentido de ampliarem a importância desse sentimento de segurança nas zonas mais nobres, tendo Sevcenko reconhecido que "a própria concepção de segurança pública se subordina a esse critério geográfico, atuando com prioridade" (Sevcenko, 1983, p. 34).

Nesse ponto, o sensacionalismo propagado pela imprensa da época na veiculação de notícias sobre incêndios em cinemas chocava-se justamente com o sentimento de segurança pretendido nas áreas centrais em relação à elite e aos setores médios privilegiados em sua circulação pelo espaço urbano pós-reforma. Os corpos carbonizados, queimados, os cinemas destruídos, as descrições horripilantes, a indiferença das autoridades policiais e municipais, a precariedade dos bombeiros - tudo funcionava como signo de disseminação do medo em relação ao ato de ir ao cinema, mesmo na parte mais privilegiada do Rio de Janeiro.

\section{CONSIDERAÇÕES FINAIS}

Em se tratando dos incêndios veiculados pela imprensa no período avaliado, podemos verificar que o sensacionalismo foi articulado como prática de comunicação nas narrativas dos jornais durante a Belle Époque carioca. Dada a qualidade do material utilizado nas películas, os incêndios durante projeções cinematográficas passaram a ocorrer logo em seguida ao momento de sua propagação pelo espaço urbano, gerando medo em sujeitos de vários grupos sociais.

Em sua mediação entre leitores/espectadores de cinema, donos de cinematógrafos e autoridades, os jornalistas valeram-se de diversas marcas de sensacionalismo, tais como descrições minuciosas de aspectos escatológicos ligados ao corpo humano, de como os incêndios ocorriam de forma espetacular, rápida e avassaladora, do desespero das vítimas ao tentarem escapar das chamas, além de veicularem imagens nos espaços privilegiados dos jornais e revistas (capa ou primeiras páginas em continuidade a ela) que visavam 
despertar um sentimento de medo relacionado ao horror (corpos queimados e carbonizados).

As transformações pelas quais o Rio de Janeiro passou nos primeiros anos do século XX também se mostraram relevantes na veiculação dessas narrativas marcadas pelo sensacionalismo e na ampliação do público do lazer cinematográfico. Noticiados em um primeiro momento em jornais e revistas voltados ao público de elite, uma vez que a projeção de imagens também o era ao chegar ao Rio de Janeiro, a ampliação do público para os setores médios e, de forma irregular, às classes mais baixas permitiu aos jornalistas a veiculação de medos que ultrapassavam o contato com a tecnologia do cinematógrafo.

Podemos afirmar que, por ocasião das notícias sobre incêndios em cinemas, a relação com as autoridades na Primeira República era perpassada por uma imaginação melodramática, na medida em que essas ações da burocracia estatal eram retratadas a partir de polos antagônicos e dotados de forte carga moral positiva ou negativa, e a sua principal característica - a indiferença - era acentuada pelo sensacionalismo da cobertura jornalística.

Desse modo, o sensacionalismo vê dissipada a sua carga negativa em relação ao domínio do popular, conectando-se aos processos de fluxo da informação e de transformação da paisagem urbana experimentados por diversos grupos sociais para emergir como uma prática de comunicação bastante presente no Rio de Janeiro da Belle Époque, que assim nos permite acessar as disposições de comportamento dos sujeitos do passado.

\section{REFERÊNCIAS}

ARAÚJO, Vicente de Paula. A Bela Época do cinema brasileiro. São Paulo: Perspectiva, 1985.

BECKER, Howard. Outsiders: estudos de sociologia do desvio. Rio de Janeiro: Jorge Zahar, 2008.

BENCHIMOL, Jayme Larry. Pereira Passos: um Haussmann tropical. Rio de Janeiro: Secretaria Municipal de Cultura, Turismo e Esportes, 1992.

BERNARDET, Jean Claude. Historiografia clássica do cinema brasileiro: metodologia e pedagogia. São Paulo: Annablume, 2004.

BOURDIEU, Pierre. A distinção: crítica social do julgamento. São Paulo: Zouk, 2011. BROOKS, Peter. The Melodramatic Imagination: Balzac, Henry James, Melodrama, and the Mode of Excess. New Haven: Yale University Press, 1995.

CARVALHO, José Murilo de. Os bestializados: o Rio de Janeiro e a república que não foi. São Paulo: Companhia das Letras, 1987. 
CAULFIELD, Sueann. Em defesa da honra: moralidade, modernidade e nação no Rio de Janeiro. Campinas: Ed. Unicamp, 2000.

DELUMEAU, Jean. História do medo no Ocidente: 1300-1800, uma cidade sitiada. São Paulo: Companhia das Letras, 1989.

DOUGLAS, Mary; ISHERWOOD, Baron. O mundo dos bens: para uma antropologia do consumo. Rio de Janeiro: Ed. UFRJ, 2004.

ENNE, Ana Lúcia. O sensacionalismo como processo cultural. Revista Eco-pós, Rio de Janeiro: UFRJ, v. 10, n. 2, p. 70-84, jul./dez. 2007.

ENNE, Ana Lúcia; BORGES, Wilson. Sensacionalismo e modernidade: como uma relação intrinsicamente ambígua se transformou em estratégia de distinção cultural? Revista Rumores, São Paulo: USP, v. 1, n. 1, p. 1-14, 2007.

GAY, Peter. A educação dos sentidos: a experiência burguesa da Rainha Vitória a Freud. São Paulo: Companhia das Letras, 1989.

GAY, Peter. O século de Schnitzler: a formação da cultura de classe média (1815-1914). São Paulo: Companhia das Letras, 2002.

GINZBURG, Carlo. Mitos, emblemas, sinais. São Paulo: Companhia das Letras, 2007. HERZFELD, Michael. The Social Production of Indifference: Exploring the Symbolic Roots of Western Bureaucracy. Chicago: The University of Chicago Press, 1992.

HOLANDA, Sérgio Buarque de. Raízes do Brasil. São Paulo: Companhia das Letras, 2004.

JAUSS, Hans Robert. A Estética da recepção: colocações gerais. In: LIMA, Luiz Costa. A literatura e o leitor: textos de estética da recepção. Rio de Janeiro: Paz e Terra, 2002. p. 67-84.

LAPERA, Pedro Vinicius A. A encenação da discórdia: consumo cinematográfico e a formação de uma cultura de classe média na Belle Époque carioca. Tempo, Niterói: UFF, v. 24, n. 1, p. 21-40, jan./abr. 2018.

MARTÍN-BARBERO, Jesús. Dos meios às mediações: comunicação, cultura e hegemonia. Rio de Janeiro: Ed. UFRJ, 2003.

MILLER, Daniel. Material Culture and Mass Consumption. New York: Blackwell, 1987. MUSSER, Charles. The Emergence of Cinema: The American Screen to 1907. v. 1. Berkeley: University of California Press, 1994.

PARK, Robert. The Natural History of the Newspaper. In: PARK, Robert. The City: Suggestions for Investigation of Human Behavior in the Urban Environment. Chicago: The University of Chicago Press, 1967.

SCHWARTZ, Vanessa. Spectacular Realities: Early Mass Culture in Fin-de-siècle Paris. Berkeley: University of California Press, 1999.

SEVCENKO, Nicolau. Literatura como missão: tensões sociais e criação cultural na Primeira República. São Paulo: Brasiliense, 1983.

SEVCENKO, Nicolau. A Revolta da Vacina: mentes insanas em corpos rebeldes. São Paulo: Brasiliense, 1984. 
SINGER, Ben. Melodrama and Modernity: Early Sensational Cinema and its Contexts.

New York: Columbia University Press, 2001.

SÜSSEKIND, Flora. Cinematógrafo de letras: literatura, técnica e modernização no

Brasil. São Paulo: Companhia das Letras, 2006.

THOMPSON, Edward P. A formação da classe operária inglesa: a árvore da liberdade.

São Paulo: Paz e Terra, 2004.

\section{NOTAS}

${ }^{1}$ In: O Rádio, Rio de Janeiro, 8 jul. 1910, p. 4.

${ }^{2}$ Sem data precisa, mas editado em janeiro de 1899, o que se pode comprovar pela reprodução de notas veiculadas na imprensa entre 6 e 7 de janeiro de 1899.

3 "Assistevano i representanti della stampa, numerose signore della migliore società, molto publico" (trad. nossa).

${ }^{4}$ Para fins deste artigo, consideramos a Belle Époque um momento de profunda transformação social e cultural que o Rio de Janeiro atravessou nas últimas décadas do século XIX e nas primeiras décadas do século XX, filiando-nos ao exposto por SEVCENKO $(1983 ; 1984)$.

${ }^{5}$ Sobre revoltas populares e motins durante a Primeira República, conferir CARVALHO (1987) e SEVCENKO (1984).

${ }^{6}$ A título de exemplo, podemos citar: "Ainda o grande incendio de hontem no Cinema Brazileiro". A Época, 10 dez. 1912, p. 2; "Fogo em um cinema: imprudencia de um menor". A Imprensa, 20 dez. 1910, p. 1; “A Última fita: O Rio Branco em chamas". Correio da Manhã, 8 jul. 1910, p. 3; "O incendio do cinema: dous predios destruídos”. Jornal do Brasil, 9 jul. 1910, p. 7.

${ }^{7}$ Piedade é um bairro da Zona Norte do Rio de Janeiro às margens da linha férrea da Central do Brasil, localizado entre os bairros Abolição, Engenho de Dentro e Quintino. 